MATEC Web of Conferences 22,05025 (2015)

DOI: $10.1051 /$ matec conf/ 20152205025

(C) Owned by the authors, published by EDP Sciences, 2015

\title{
Research on Bored Bearing Characteristics in Xi'an
}

\author{
Lipeng Zhang*, Yabin Shen, Duanduan Wang \\ School of Highway, Chang'an University, Xi'an, Shaanxi, China
}

\begin{abstract}
To analyze the influence of different soil properties on pile foundation load-bearing characteristics, taking a section of railway in Xi'an and a bridge of Xi'an as test area, and by field static load test to study load transfer characteristics after the test piles under axial pressure, including the distribution of axial force, pile lateral friction, tip resistance traits, ultimate bearing capacity determine, and compare with the theory bearing capacity. Experimental results show that, adjacent soil properties change large, axial force and lateral friction mutation at the junction of corresponding soil layer. Silty clay in different parts is below ground, and its lateral friction plays much difference. Pile lateral friction plays an important role in bearing capacity, but the role of round gravel soil end bearing capacity to pile bearing capacity can't be ignored. Tests calculate pile bearing capacity significantly larger than standardized formula calculation bearing capacity, which are respectively $55.35 \%$ and $119.1 \%$. And give the similar project condition the suggested values of pile bearing capacity and soil friction, to provide reference for similar pile foundation design.
\end{abstract}

Keywords: bored pile, pile lateral friction, pile tip resistance, capacity

\section{INTRODUCTION}

Bored piles have been widely applied to engineering practice, as those advantages of simple construction equipment is easy to operate, and widely applied, altering the pile length according to the stratigraphic distribution optionally, and expanding pile bottom to give full play to the strength of pile body and the bearing capacity of subsoil ${ }^{[1]}$. Due to the numerous and complicated factors affecting the bearing capacity of pile foundation, different designers may have large differences in selecting parameters in the process of pile foundation design. The Code for Design of Ground Base and Foundation of Highway Bridges and Culverts gives the provisions that the value of bridge pile lateral friction and pile tip resistance should be confirmed through the single pile vertical compressive static load test.

In this paper typical test piles in two test areas were chosen by comparing and analyzing the test data, to provide basis and reference for the design calculation and the future research of bored pile bearing capacity in the region.

\section{EXPERIMENT}

\subsection{Engineering geological profile}

The Xi'an section of this railway has a total length of $32.4 \mathrm{~km}$. Along this section, large and super-large bridges account for about 5\%. A super-large bridge has a total length of 1713 meters, in these two experimental zones, the pile foundation holes were made by spiral drill, and swell pulping was used to protect the wall of holes. According to the geological *Corresponding author: 772797602@,qq.com survey report (refer to Table 1), the main layer formation of a railway consists of silty clay, round gravel soil, land pebble, and the main formation of a railway viaduct test area consists of silty clay and medium sand.

\subsection{Test pile parameters}

Each test area has 3 piles which are named S1, S2, and S3. The effective length of the test piles in the experimental zone of a super large bridge is $21.5 \mathrm{~m}$, and the actual length is $23 \mathrm{~m}$. In Xi'an experimental zone of a railway the effective length of the test piles is $26.5 \mathrm{~m}$, and the actual length is $28 \mathrm{~m}$. The diameter of the test pile in these two experimental zones is $1.0 \mathrm{~m}$, and the pile body is made of $\mathrm{C} 30$ concrete. The main reinforcement is composed of 16 HRB335 reinforced, and diameter is $25 \mathrm{~mm}$, stirrups are arranged along the main reinforcement using R235 reinforced, the diameter of the stirrups is $8 \mathrm{~mm}$, and the reinforced hoops are arranged every $2 \mathrm{~m}$, using HRB335 reinforced with a $25 \mathrm{~mm}$ diameter.

In order to get more accurate test results, the diameter size and integrity of these piles should be tested. And the diameter size of the test pile influences the body strain of these piles directly, simultaneously, it can also influence the ultimate bearing capacity of the pile in playing. In order to obtain accurate test results, the measured diameter of the test pile must be correct, and the factors of pile diameter that influence the results must be eliminated. The pile body completeness inspection is tested by ultrasonic method, through analyzing the testing datum, and the test piles can be determined to be eligible piles, and the classes of the pile foundations is class I. 
MATEC Web of Conferences

Table 1. Geological data

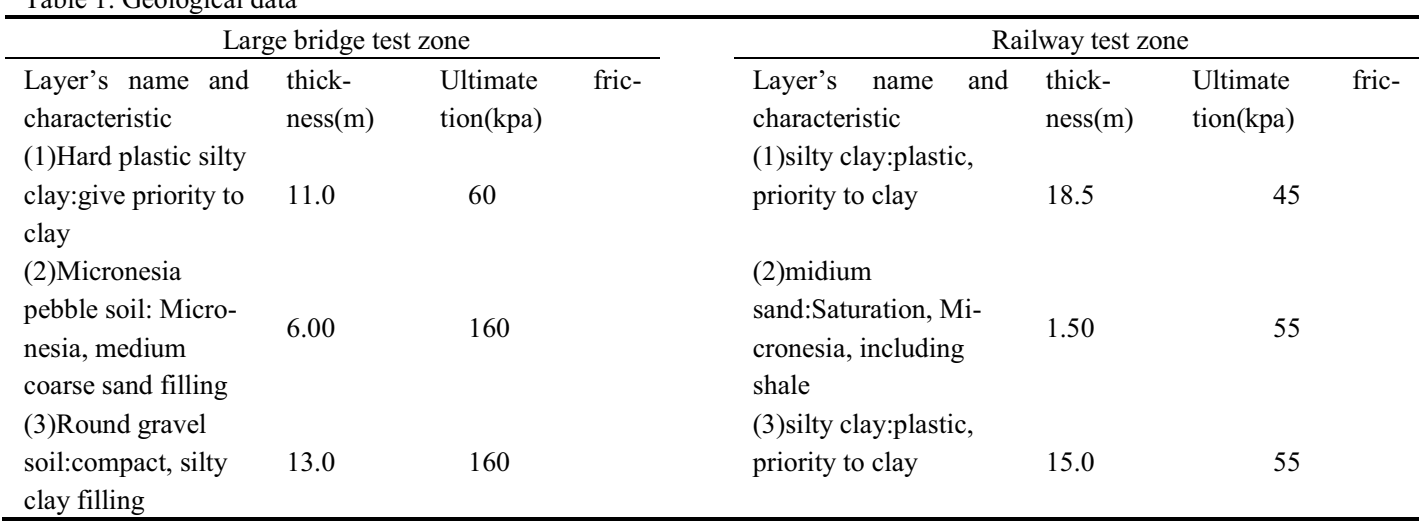

\subsection{Loading way and the determination of settlement} stability

The bearing capacity of piles in a super major bridge test zone is $12629 \mathrm{kN}$ by estimating, and in a viaduct test the bearing capacity of piles is estimated $7830 \mathrm{kN}$. In order to give full play to the ultimate bearing capacity of test piles, the test pile is loaded until it damages, in both of the super major bridge and the railway zone. The highest load grade for the bridge is 8 th grade, and the grade is classified every $2500 \mathrm{kN}$, the railway load grade is classified every $1000 \mathrm{kN}$

In the two experimental zones, the vertical bearing zones, and the vertical bearing capacity of single pile is tested by anchor pile beam counterforce device. Loaded in a slow load maintain way, namely step by step load, when loading the number on the instruments panel which should be written down every $5,10,15,15,15$ minutes, after $1 \mathrm{~h}$ the data can be written every 30 minutes, when the settlement of pile top is less than $0.1 \mathrm{~mm}$ every $1 \mathrm{~h}$, and it appears twice in a row, and each grade load can hold not less than $2 \mathrm{~h}$, and then the settlement can be regarded as that it has reached a relatively stable condition, and then the next load grade can be added until the terminative loading condition is reached, and then the load can be shed to zero.

\section{COMPARSION AND ANALYSIS OF TEST RESULTS}

\subsection{Specialties of pile's bearing capacity}

The ultimate bearing capacity of single pile is controlled by soil bearing capacity to the pile on it, and the strength of pile body's material and the settlement of the structure on the single pile are allowed. The above three aspects can be reflected through the settlement of pile top.

After the vertical compressive static load test, test the pile's integrity using a small strain gauge, and no abnormalities were found, and then a conclusion can be gotten that the concrete of pile is well, but the pile soil system was damaged. Q-S curve of each test pile is as shown in Figure 1.

A conclusion can be gotten from the curve of load-settlement and pile top settlement data that the settlement of six test piles increased sharply when the maximum load was loaded, and there is a significant drop point on the curve. The bridge pile S1 keeps subsiding under the $20000 \mathrm{kN}$ load, and a sharp decline happens to the pile top settlement, and the total settlement is about $63 \mathrm{~mm}$. This phenomenon implies that the test pile S1 has been damaged. It's the same to the test pile S2 and S3. When they were loaded to $20000 \mathrm{kN}$, the settlement of pile increased rapidly, and the loading system cannot maintain a normal load, and then it can be determined that the ultimate bearing capacity of S1, S2, $\mathrm{S} 3$ is $17500 \mathrm{kN}$, and in a railway zone the cumulative settlement of test pile $\mathrm{S} 1$ is $29.349 \mathrm{~mm}$, when the load is $7000 \mathrm{kN}$. When the load to $8000 \mathrm{kN}$, the test pile settlement continues to enlarge, and the ruler of the settlement of pile top is about $63 \mathrm{~mm}$, determining the test pile $\mathrm{S} 1$ is damaged, which is the same to the test pile $\mathrm{S} 2$ and $\mathrm{S} 3$, when load to $8000 \mathrm{kN}$ has shown a significant decline, thus determining the ultimate capacity of $\mathrm{S} 1, \mathrm{~S} 2, \mathrm{~S} 3$ is $7000 \mathrm{kN}$.

\subsection{Excitation and characteristics of the axial force of pile and pile tip resistance}

As we can see from Figures 2 and 3, under different loads, the axial force decreases as the depth of the pile decreases, indicating that as the vertical load passing is down, due to the pile lateral soil resistance, most of the load is transferred to the pile side soil, and it also shows that the pile lateral friction has played when the pile tip resistance plays ${ }^{[3]}$.

For the bridge test, the axial force of pile decreases nonlinearly as the depth increases, and it's linear when the depth is smaller than $11 \mathrm{~m}$, and nonlinear when the depth is bigger than $11 \mathrm{~m}$. The reason for this is that the quality of soil changes greatly, and above $11 \mathrm{~m}$ it is hard plastic silty clay layer, but between $11 \sim 17 \mathrm{~m}$, existence of the dense gravel soil makes the difference between the two layers. The friction resistance is $110 \sim 140 \mathrm{kpa}$, that is, with piles buried depth increases, 
especially the depth in the supporting layer and shows the depth effect. For the railway, the axial force of pile decreases linearly as the depth increases, because geosphere distribution uniform and the nature of the soil changes little, the interlayer (sand) depth is only $1.5 \mathrm{~m}$.

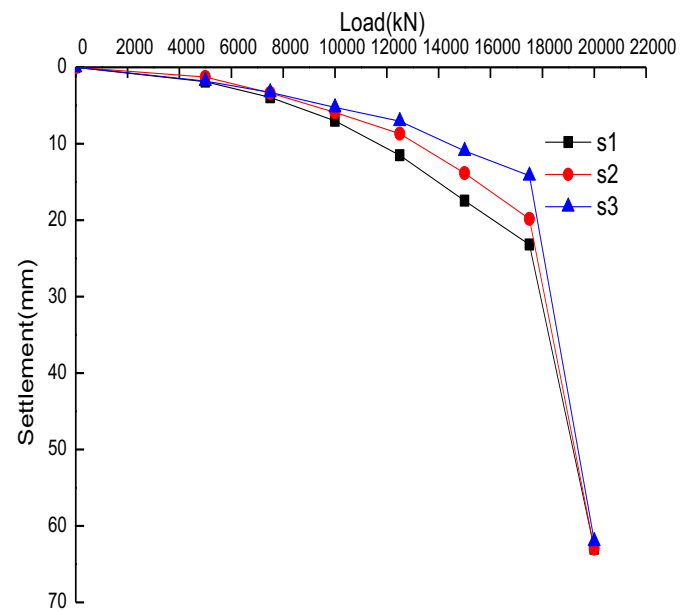

(a)Q-S curve of test pile in a large bridge zone

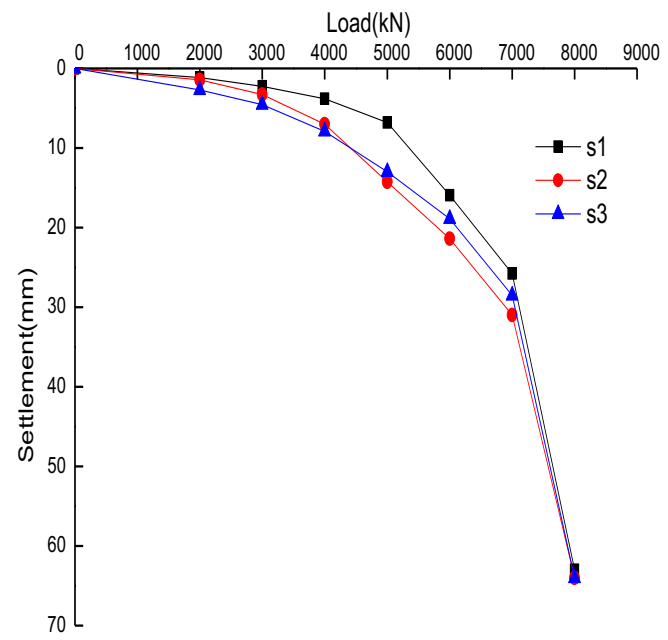

(b)Q-S curve of test pile in railway zone

Figure 1. The Q-S curve of Tested pile

The excitation of pile tip resistance and the increases of load on pile top have a nonlinear relationship, showing the characters of time lag ${ }^{[3]}$, and the pile tip resistance can't be detected when the load of a bridge test pile is less than $4000 \mathrm{kN}$, which is the same to the railway test pile when the load is less than $2000 \mathrm{kN}$, indicating that when the load is small, the load is mainly supported by the pile lateral friction resistance, and the pile tip resistance grows slowly. With the increase of the load, when the load of a bridge is over $7500 \mathrm{kN}$, a railway load is bigger than $3000 \mathrm{kN}$, and the pile tip resistance is excited, when the load reaches to the ultimate, the pile tip resistance of a bridge accounts for $12.3 \%$ of the total load, the pile tip resistance of a railway accounts for $6.4 \%$ of the total load, indicating that the load is mainly carried by the pile friction and pile tip resistance is small, and this test shows the mechanical property of friction pile [4].

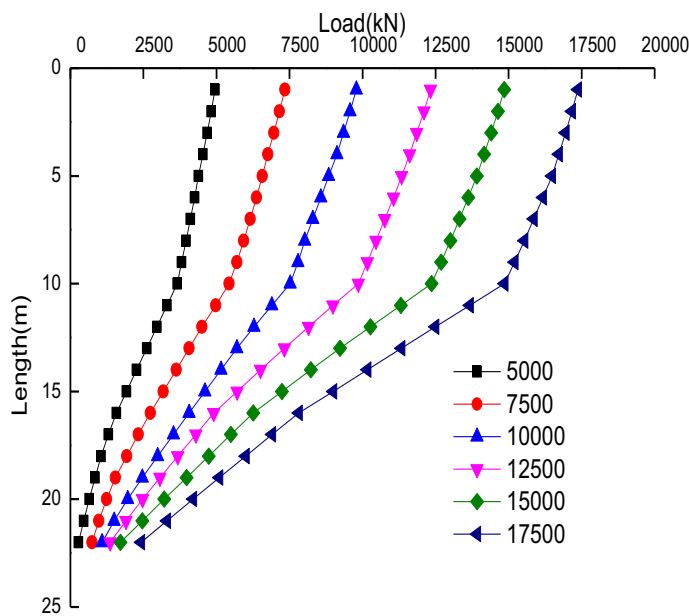

(a)Axial force curve of test pile in a large bridge zone

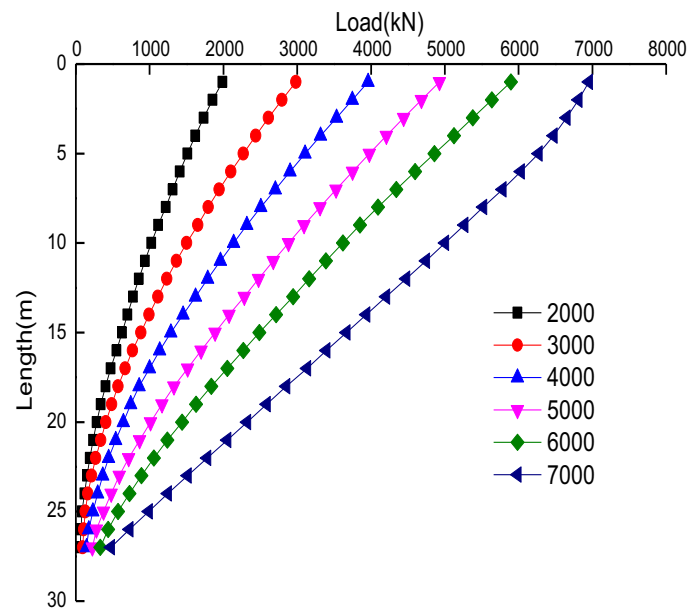

(b)Axial force curve of test pile in railway zone

Figure 2. Test results of axial force of pile

\subsection{Excitation and characteristics of pile lateral friction}

As can be seen from Figure 4, because of the difference of the pile side soil engineering properties, the pile friction distribution of each soil is different. As the increase of the load, the exerting degree of the pile 
lateral friction increases gradually.

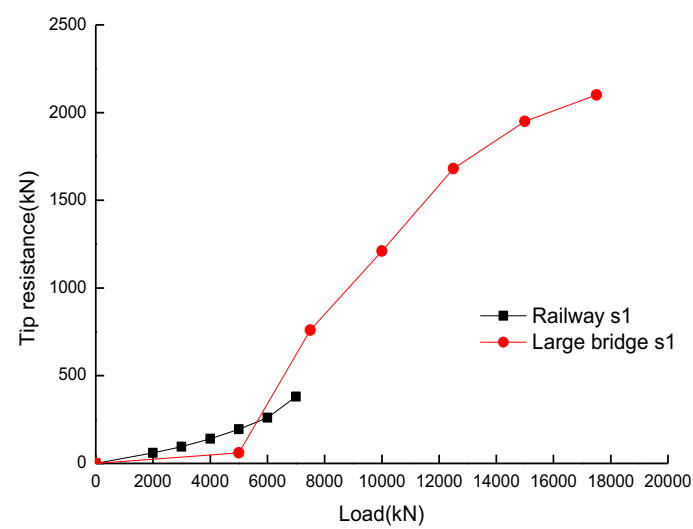

Figure 3. Distribution curve of pile tip resistance

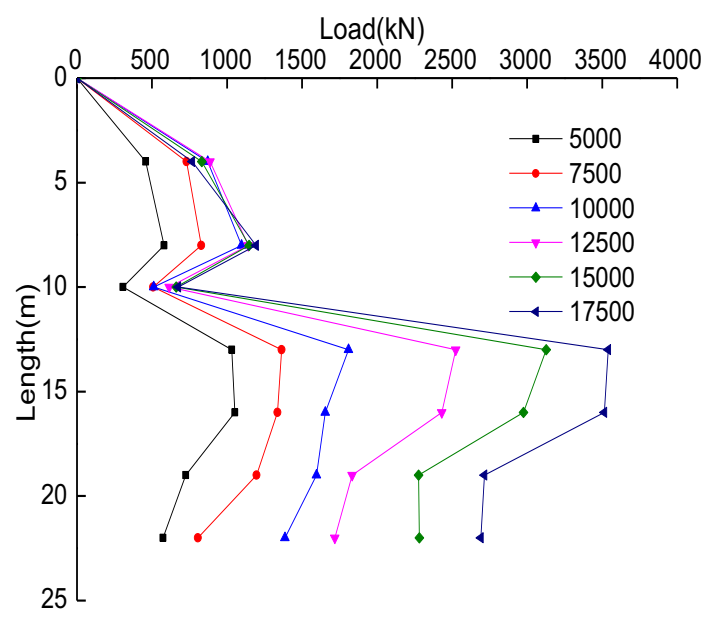

(a)Axial force curve of test pile in a large bridge zone

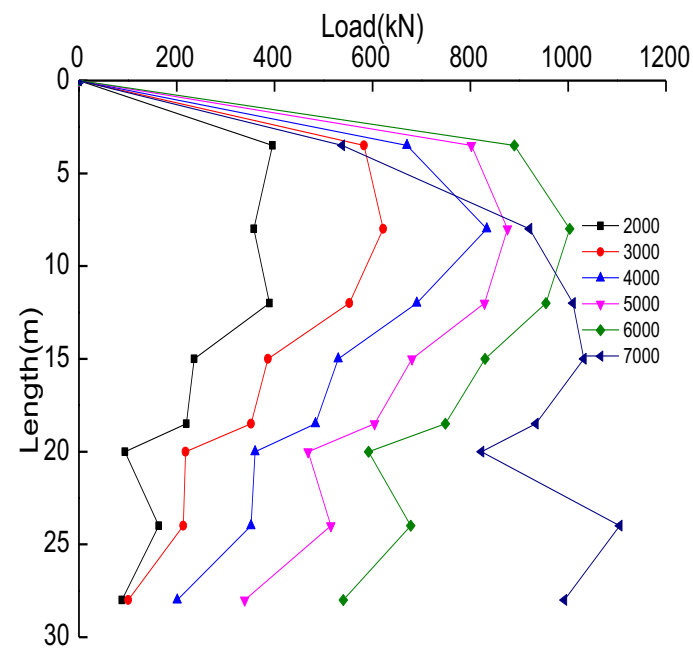

(b)Axial force curve of test pile in railway zone
Figure 4. Skin friction distribution of test pile

For the entire, the lateral friction resistance of a bridge pile increases firstly and then decreases along the pile, so the pile friction in the middle depth is larger and smaller in both ends, and with the increase of the pile loading stage, the frictional resistance profile shows a trend of gradually going back ${ }^{[4]}$, because of the soil properties changing at the pile $11 \mathrm{~m}$ gravel layer. Above $11 \mathrm{~m}$, it is the hard plastic silty clay layer, and in the area of $11 \sim 17 \mathrm{~m}$ it is the dense gravel layer, and below $17 \mathrm{~m}$ it is the round gravel soil, and the norm frictional resistance bridge pile increases firstly and then decreases along the pile, so the pile friction in the middle depth is larger and smaller in both ends.

The pile lateral friction distribution difference of railway is smaller than the bridge, because the soil properties around the pile are similar, and the pile lateral friction along the pile increases at first and then decreases.

The decreasing processes relatively uniform the pile lateral friction in the third clay layer which is smaller than layer one, and it reveals that depth affects the play of pile friction. The confining pressure plays a great favor for pile lateral friction play, and many international norms are generally considered that pile friction is not only related to the adhesion and friction angle between soil and pile, but also the effective of overburden pressure considers the depth ${ }^{[3]}$. When the load is $7000 \mathrm{kN}$, the pile lateral friction is small compared with the previous load level in the depth of about $2 \sim 8 \mathrm{~m}$, and return to the normal under $8 \mathrm{~m}$. Because the biggest pile friction occurs on the top of the pile under the initial loading. As the settlement of the pile tip increases, when the settlement of pile tip beyond that the soil required to play the extremity friction resistance, coupled with the soil at the top of the pile was disturbed, and frictional resistance at the top of the pile began to decline, and then the pile friction maximum position will decline.

\subsection{Analysis of the factors influencing the bearing capacity of pile foundation}

1) For the friction pile, the soil properties that the pile through have a great influence on pile bearing capacity, the test pile of the bridge and railway has fully proved that different pile side soil properties have different effects on the bearing capacity. The greater friction resistance of pile side soil can provide, the higher the bearing capacity of pile is.

2) The different natures of the bearing layer will have different influences on the bearing capacity. The bridge test area of pile end bearing layer is the circular gravel, and the test value is greater than the normal value, and the bearing capacity of bearing force layer is affected not only by the properties of soil and the pile length-diameter ratio and also by the modulus ratio of pile and soil. If the pile is too long, the pile 
ICETA 2015

\begin{tabular}{lllll}
\multicolumn{2}{l}{ Table 2. Comparative table of allowable bearing capacity of pile } & & \\
\hline number & test area & Explore value $(\mathrm{kN})$ & Test value $(\mathrm{kN})$ & $\begin{array}{l}\text { Suggest } \\
\text { ue }(\mathrm{kN})\end{array}$ \\
\hline 1 & Bridge test area & 4557 & 9987 & 6146 \\
2 & railway test area & 2406 & 3738 & 3228 \\
\hline
\end{tabular}

Note: Allowable value of bearing capacity of single friction pile under axial compression

$$
\left[R_{a}\right]=\frac{1}{2} u \sum_{i=1}^{n} q_{i k} l_{i}+A_{p} q_{r} q_{r}=m_{0} \lambda\left[\left[f_{a 0}\right]+k_{2} \gamma_{2}(h-3)\right]
$$

Table 3. Recommended value of friction and pile bearing capacity

\begin{tabular}{|c|c|c|c|c|c|c|c|c|}
\hline \multirow[t]{2}{*}{ name } & \multirow{2}{*}{$\begin{array}{l}\text { Geotechnical state or } \\
\text { density }\end{array}$} & \multicolumn{4}{|c|}{ friction force value [qik] $(\mathrm{kPa})$} & \multicolumn{3}{|c|}{$\begin{array}{l}\text { Pile bearing capacity allowable } \\
\text { value }[\mathrm{fao}](\mathrm{kPa})\end{array}$} \\
\hline & & Norm & Explore & Test & Suggest & Explore & Test & Suggest \\
\hline land pebble & $\begin{array}{l}\text { Moder- } \\
\text { ate density ,Saturation }\end{array}$ & $160 \sim 220$ & $150 \sim 170$ & 372 & $220(250)$ & - & - & 一 \\
\hline $\begin{array}{l}\text { Round } \\
\text { gravel soil }\end{array}$ & dense,Saturation & $150 \sim 180$ & $150 \sim 170$ & 287 & $180(200)$ & $450 \sim 550$ & 4335 & 800 \\
\hline Silty clay & plasticity Saturation, & $50 \sim 80$ & $40 \sim 50$ & 73 & 65 & - & - & - \\
\hline silly ciay & Hard plastic & $50 \sim 80$ & $50 \sim 65$ & 83 & 75 & $160 \sim 220$ & 380 & 270 \\
\hline
\end{tabular}

Note: The column of recommended data in brackets is applied to super major bridge project. The results of this table can be applied to the spiral drill hole pile foundation directly. For other pile foundation the selection of design parameters should be taken full account of the differences in the construction process.

axial force passes to the bearing layer of pile is small, and the resistance value is relatively small.

3) The soil parameters that geological exploration report provides is smaller than the practical test measured, resulting in the actual pile foundation bearing capacity estimation is too low. In addition, the strength of the pile, the pile bottom sediment and the pile side mud, and all of those have different influences on pile bearing.

\subsection{Pile bearing capacity Suggested values}

In the early of pile foundation designation, the calculation of the bearing capacity generally refers to the standard values of the similar test data. Compare the test results and the calculation of the bearing capacity of the piles, it appears that the bearing capacity is estimated low. Allowable value of single pile's axial force is compared in Table 2. Refer to the test data, and provide round gravel soil, gravel and silty clay soil pile frictional resistance and pile bearing capacity suggest values (refer to Table 3 ).

From Table 2, we can see that there are much difference between explore value and test value, and the bearing capacity test value of bridge test area is $5430 \mathrm{kN}$ higher than explore value, which is $124.07 \%$ higher. The bearing capacity test value of railway test area is $1332 \mathrm{kN}$ higher than explore value, which is $55.36 \%$ higher. By Table 2, we know that there is much difference between explore value and test value, and the reasons are as follows.

1) There are many affect factors that have an influence on bearing capacity, such as construction method, pile diameter and pile length, and the relationship between these factors can't be accurately determined.

2) There are some errors in the explore value, and the explore value is a mean value, which also shows that the reason why different designer chooses different parameter during design.

In Table 3, the norme, explore, suggest friction values were given and the norme, explore, suggest bearing capacity allowable value were given. By Table3, we can know that there are much difference between normal and test. The norm friction value of land pebble between $160-220$, the test friction value is 372 , higher than 152-212, given that the suggest value is $220(250)$. The lateral friction of silty clay between norm value and test value is close. The norm lateral friction of round gravel soil is $150-180$, and the test value is 287, given that the suggest value is 180(200).

\section{CONCLUSIONS}

1) The soil properties around pile have an much influence on the load transferring character when loaded the axial load. When the pile side soil properties change much, the axial force and lateral friction changes greatly, but it isn't contrary.

2) The majority of pile bearing capacity is the pile lateral friction resistance, but the end bearing capacity of pile cannot be ignored, and the end bearing capacity of round gravel soil test values is $688.18 \%$ higher than the investigation, and the end bearing capacity of hard plastic silty clay test values is $72.7 \%$ higher than the investigation, and this part of the bearing capacity of 
the pile can be used as a safety margin, showing that the code is too conservative.

3 ) When silty clay is in different parts of the below ground, there is a great different extent of pile lateral friction, showing that the soil location have much influence on pile lateral friction. When confronting this condition, the lateral friction value should be considered as enhance coefficient.

4) Bearing capacity of pile in experiment is significantly larger than the normal value, and the experimental allowable bearing capacity of a bridge pile is $119.1 \%$ higher than the investigation value. The experimental allowable bearing capacity of a railway pile is $55.3 \%$ higher than the exploration and design value. The lateral friction of gravel soil test values is $69.1 \%$ and $118.88 \%$ higher than the normal, survey values. Pile side round skin friction of round gravel soil test values are $59.4 \%$ and $68.8 \%$ higher than the investigation, standard value, and silty clay pile lateral friction test values and standard values is similar, but it's $46.0 \%$ and $27.7 \%$ higher than the Survey values, for those have the similar engineering geological conditions and pile foundation nature, given the recommended values of permissible bearing capacity of pile foundation, so that a reference and basis for the similar engineering are provide.

\section{REFERENCES}

[1] WANG Xiaomou. 2003. Foundation Engineering. 4th ed. Beijing: China Communications Press.

[2] JTG D63 - 2007, Code for Design of Ground Base and Foundation of Highway Bridges and Culverts.

[3] Niu Fusheng, Wang Xiaomou. \& Zhao Hong, et al. 2012. Experimental Research on Static Load of Xianyang Airport Overpass on Yongshou-Xianyang Expressway. Journal of Highway and Transportation Research and Development, 29(11): 45-52.

[4] Feng Zhongju, Xie Yongli. \& Li Zhe, et al. 2005. Bearing property of large-diameter over-length nonplacement pile. Journal of Traffic and Transportation Engineering, 5(1): 24-27.

[5] Zou Dongfeng. 2013. Behaviors of bearing capacity of ultra-long bored piles. Chinese Journal of Geotechnical Engineering, 35(7): 1-5.

[6] GB 50007-2002, Code for Design of Building Foundation.

[7] Wang Duanduan, Jia Li. \& Li Guoqi. 2013. Comparative analysis on bearing capacity test of post-grouting pile foundation. Coal Geology \& Exploration, 41(3): 45-52.

[8] Shi Peidong. 1999. Practical Handbook for Pile Foundation Engineering. Beijing: China Architecture and Building Press.

[9] Youn H J. \& Tonon F. 2010. Numerical analysis on post-grouted drilled shaft: A case study at the Brazo River Bridge. Computers and Geotechnics, 37(4): 456-465.

[10] Ahmadi M M. \& Khabbazian M. 2009. End Bearing Capacity of Drilled Shafts in Sand: A Numerical Ap- proach. Geotechnical and Geological Engineering, 27(2): 195-206.

[11]Wang Xuezhi, Li Yadong, Zhao Chunfeng. 2012. Laboratory Model Test on Interaction of Pile-tip Soils and Pile-side Soils. Building Science, 28(3): 50-54.

[12]Xi Ningzhong, Liu Jinli. \& Xi Jingyi. 2011. Numerical analysis of influence of stiffness of pile tip soil on shaft resistance. Chinese Journal of Geotechnical Engineering, 33: 174-177.

[13]Zhao Minghua, Yang Minghui. \& Zou Xinjun. 2005. Vertical bearing capacity of pile based on load transfer model. Journal of Central South University of Technology, 12(4): 488-493.

[14]Liu Kun, Zhao Chunfeng. 2011. Model tests on bored piles under vertical load on different pile-tip soils. Chinese Journal of Geotechnical Engineering, 33(3): 490-495.

[15] Sun Yuxiang, Zhang Hong. \& Xiao Wenfu, et al. 2012. Key technology for construction of connection between steel pylon and concrete pile cap of middle pylon of Taizhou Bridge. Engineering Sciences, 10(3): 8-11. 